Pacific Journal of Mathematic 


\title{
ON LINEAR FORMS AND DIOPHANTINE APPROXIMATION
}

\author{
JEFFREY D. VAALER
}

\begin{abstract}
Let $\vec{x}$ be a vector in $\boldsymbol{R}^{K}$ and let $\Lambda_{j}(\vec{x}), j=1,2, \cdots, J$ be $J$
\end{abstract} linear forms in $K$ variables. We prove that there is a lattice point $\vec{u}$ in $Z^{K}, \vec{u} \neq \overrightarrow{0}$, for which $\left|\Lambda_{j}(\vec{u})\right|$ are all small (or zero) and the components of $\vec{u}$ are not too large. The bounds that we obtain improve several previous results on this problem.

1. Introduction. Let $A_{1}(\vec{x}), A_{2}(\vec{x}), \cdots, A_{J}(\vec{x})$ be $J$ linear forms in $K$ real variables $x_{1}, x_{2}, \cdots, x_{K}$. We assume that $B=\left(b_{j k}\right)$ is a $J \times K$ matrix with complex entries such that

$$
\Lambda_{j}(\vec{x})=\sum_{k=1}^{K} b_{j k} x_{k}
$$

for $j=1,2, \cdots, J$ and so $\vec{x}$ denotes the column vector $\left(\begin{array}{c}x_{1} \\ \cdots \\ x_{K}\end{array}\right)$. A basic problem in Diophantine approximation is to show that there exists a vector $\vec{u}=\left(\begin{array}{c}u_{1} \\ \cdots \\ u_{K}\end{array}\right)$ in the integer lattice $Z^{K}, \vec{u} \neq \overrightarrow{0}$, such that each $\left|\Lambda_{j}(\vec{u})\right|$ is small while the components $\left|u_{k}\right|$ are not too large. Quantitative results on this problem are known with various hypotheses on the $\Lambda_{j}$ 's; the usual method of proof involves an application of the pigeonhole principle (Baker [1], Lemma 1, p. 13, Gel'fond [3], Lemma 1, p. 11, Mordell [7], Theorem 3, p. 32, Siegel [8], Stolarsky [9], Chapter 2). In the present paper we make improvements on previous results of this kind by using a generalization of Minkowski's linear forms theorem which we established in [10].

In order to state our main theorem we make the following assumptions. We suppose that the forms $A_{j}$ are real for $j=1,2, \cdots, p$ and that the remaining forms consist of $q$ pairs of complex conjugate forms arranged so that $\Lambda_{p+2 j-1}=\bar{\Lambda}_{p+2 j}$ for $j=1,2, \cdots, q$. Thus $J=$ $p+2 q$. We also suppose that $\alpha_{k} \geqq 1$ for $k=1,2, \cdots, K, \beta_{j}>0$ for $j=1,2, \cdots, J$, and $\beta_{p+2 j-1}=\beta_{p+2 j}$ for $j=1,2, \cdots, q$.

THEOREM 1. Let $M$ be a positive integer and suppose that

$$
M^{2}\left\{\prod_{l=1}^{K} \alpha_{l}^{-2}\right\}\left\{\prod_{j=1}^{J}\left(1+\beta_{j}^{-2} \sum_{k=1}^{K} \alpha_{k}^{2}\left|b_{j k}\right|^{2}\right)\right\} \leqq 1 .
$$

Then there exist $M$ distinct pairs of nonzero lattice points $\pm \vec{v}_{m}=$ 
$\pm\left(\begin{array}{c}v_{1 m} \\ \cdots \\ v_{K m}\end{array}\right), m=1,2, \cdots, M$, in $\boldsymbol{Z}^{K}$ each of which satisfies the following conditions:

$$
\begin{gathered}
\left|\Lambda_{j}\left( \pm \vec{v}_{m}\right)\right| \leqq \beta_{j}, \quad j=1,2, \cdots, p, \\
\left|\Lambda_{j}\left( \pm \vec{v}_{m}\right)\right| \leqq\left(\frac{2}{\pi}\right)^{1 / 2} \beta_{j}, \quad j=p+1, p+2, \cdots, J, \\
\left|v_{k m}\right| \leqq \alpha_{k}, \quad k=1,2, \cdots, K .
\end{gathered}
$$

Next we deduce several corollaries to Theorem 1 which are easier to use in applications. For simplicity these results are stated for the case $M=1$.

Corollary 2. Suppose that $1 \leqq J<K$ and that the coefficients $b_{j k}$ satisfy $\left|b_{j k}\right| \leqq T$ for some positive $T$. Then for each $\beta, 0<\beta \leqq T$, there exists a lattice point $\vec{u}=\left(\begin{array}{c}u_{1} \\ \cdots \\ u_{K}\end{array}\right), \vec{u} \neq \overrightarrow{0}$, in $Z^{K}$ such that

$$
\begin{gathered}
\left|\Lambda_{j}(\vec{u})\right| \leqq \beta, \quad j=1,2, \cdots, p, \\
\left|\Lambda_{j}(\vec{u})\right| \leqq\left(\frac{2}{\pi}\right)^{1 / 2} \beta, \quad j=p+1, p+2, \cdots, J,
\end{gathered}
$$

and

$$
\left|u_{k}\right| \leqq\left(\beta^{-1} T \sqrt{K+1}\right)^{J /(K-J)}, \quad k=1,2, \cdots, K
$$

Proof. We apply Theorem 1 with $M=1, \alpha_{k}=\alpha \geqq 1$, and $\beta_{j}=$ $\beta \leqq T$. Then the left hand side of (1.1) is

$$
\begin{aligned}
\alpha^{-2 K} \prod_{j=1}^{I}\left(1+\beta^{-2} \alpha^{2} \sum_{k=1}^{K}\left|b_{j k}\right|^{2}\right) & \leqq \alpha^{2 J-2 K}\left(\alpha^{-2}+\beta^{-2} T^{2} K\right)^{J} \\
& \leqq \alpha^{2 J-2 K}\left(\beta^{-2} T^{2}(K+1)\right)^{J} .
\end{aligned}
$$

If we choose

$$
\alpha=\left(\beta^{-1} T \sqrt{K+1}\right)^{J(/ K-J)}
$$

then $\alpha \geqq 1$ and the expression on the right of (1.3) is equal to 1 . Hence the corollary follows from the theorem.

We note that in previous versions of Corollary 2 (see Gel'fond [3]) the bound on $\left|u_{k}\right|$ was

$$
\left|u_{k}\right| \leqq 2\left(\beta^{-1} T K\right)^{J /(K-J)} \text {. }
$$

However, in the special case $J=1$ a bound similar to (1.2) was 
obtained by Mahler [6].

If the coefficients $b_{j k}$ are integers we obtain an improvement in "Siegel's lemma" (Baker [1], Siegel [8], Stolarsky [9]).

CoROLlaRY 3. Suppose that $1 \leqq J<K$ and that the coefficients $b_{j k}$ are integers satisfying $\left|b_{j k}\right| \leqq T$ for some $T \geqq 1$. Then there exists a lattice point $\vec{u}=\left(\begin{array}{c}u_{1} \\ \cdots \\ u_{K}\end{array}\right), \vec{u} \neq \overrightarrow{0}$, in $Z^{K}$ such that

$$
\Lambda_{j}(\vec{u})=0, \quad j=1,2, \cdots, J,
$$

and

$$
\left|u_{k}\right| \leqq(T \sqrt{K+1})^{J /(K-J)}, \quad k=1,2, \cdots, K
$$

Proof. We apply Corollary 1 with $0<\beta<1, p=J$ and $q=0$. Since $\Lambda_{j}(\vec{u})$ is an integer whenever $\vec{u} \in Z^{K}$ it follows that there exists $\vec{u} \in Z^{K}, \vec{u} \neq \overrightarrow{0}$, such that (1.4) holds and

$$
\left|u_{k}\right| \leqq\left(\beta^{-1} T \sqrt{K+1}\right)^{J /(K-J)}, \quad k=1,2, \cdots, K .
$$

Now among the finitely many lattice points $\vec{u} \in Z^{K}, \vec{u} \neq \overrightarrow{0}$, which satisfy (1.4) and (1.5) with $\beta=1 / 2$ there must be at least one which satisfies (1.4) and (1.5) for values of $\beta$ arbitrarily close to 1 . Thus we may take $\beta=1$ on the right of (1.5) for some $\vec{u} \in \boldsymbol{Z}^{K}, \vec{u} \neq \overrightarrow{0}$.

Corollary 4. Suppose that $1 \leqq J<K$ and that $H_{1}, H_{2}, \cdots, H_{K}$ are positive integers. Then there exists a lattice point $\vec{u}=\left(\begin{array}{c}u_{1} \\ \cdots \\ u_{K}\end{array}\right)$, $\vec{u} \neq \overrightarrow{0}$, in such that

$$
\begin{gathered}
\left|u_{k}\right| \leqq H_{k}, \quad k=1,2, \cdots, K, \\
\left|\Lambda_{j}(\vec{u})\right| \leqq \frac{2\left(\sum_{k=1}^{K} H_{k}^{2}\left|b_{j k}\right|^{2}\right)^{1 / 2}}{\left(\prod_{k=1}^{K} H_{k}\right)^{1 / J}}, \quad j=1,2, \cdots, p, \\
\left|\Lambda_{j}(\vec{u})\right| \leqq \frac{2\left(\frac{2}{\pi}\right)^{1 / 2}\left(\sum_{k=1}^{K} H_{k}^{2}\left|b_{j k}\right|^{2}\right)^{1 / 2}}{\left(\prod_{k=1}^{K} H_{k}\right)^{1 / J}}, \quad j=p+1, p+2, \cdots, J .
\end{gathered}
$$

Proof. Let $0<\theta<1$. We apply Theorem 1 with $M=1, \alpha_{k}=$ $H_{k}+\theta$ and

$$
\beta_{j}=\psi_{\theta}\left(\sum_{k=1}^{K} \alpha_{k}^{2}\left|b_{j k}\right|^{2}\right)^{1 / 2}
$$


where

$$
\psi_{\theta}=\left\{\prod_{k=1}^{K}\left(H_{k}+\theta\right)^{2 / J}-1\right\}^{-1 / 2}
$$

It follows that the left hand side of (1.1) is

$$
\prod_{l=1}^{K}\left(H_{l}+\theta\right)^{-2}\left(1+\psi_{\theta}^{-2}\right)^{J}=1 \text {. }
$$

Thus there exists $\vec{u} \in Z^{K}, \vec{u} \neq \overrightarrow{0}$, such that

$$
\begin{gathered}
\left|u_{k}\right| \leqq H_{k}, \quad k=1,2, \cdots, K, \\
\left|\Lambda_{j}(\vec{u})\right| \leqq \psi_{\theta}\left(\sum_{k=1}^{K}\left(H_{k}+\theta\right)^{2}\left|b_{j k}\right|^{2}\right)^{1 / 2}, \quad j=1,2, \cdots, p,
\end{gathered}
$$

and

$$
\begin{array}{r}
\left|\Lambda_{j}(\vec{u})\right| \leqq\left(\frac{2}{\pi}\right)^{1 / 2} \psi_{\theta}\left(\left.\left.\sum_{k=1}^{K}\left(H_{k}+\theta\right)\right|^{2} b_{j k}\right|^{2}\right)^{1 / 2}, \\
j=p+1, p+2, \cdots, J .
\end{array}
$$

Only finitely many $\vec{u} \in Z^{K}, \vec{u} \neq \overrightarrow{0}$, satisfy (1.6) and so, as in the proof of Corollary 3, at least one of these lattice points must satisfy (1.7) and (1.8) for all $\theta, 0<\theta<1$. Thus we may take $\theta=1$ on the right hand side of (1.7) and (1.8). Finally we observe that

$$
\left(\sum_{k=1}^{K}\left(H_{k}+1\right)^{2}\left|b_{j k}\right|^{2}\right)^{1 / 2} \leqq 2\left(\sum_{k=1}^{K} H_{k}^{2}\left|b_{j k}\right|^{2}\right)^{1 / 2}
$$

and

$$
\psi_{1}=\left(\prod_{k=1}^{K} H_{k}\right)^{-1 / J}\left\{\prod_{l=1}^{K}\left(1+H_{l}^{-1}\right)^{2 / J}-\prod_{l=1}^{K} H_{l}^{-2 / J}\right\}^{-1 / 2} \cdot
$$

Since $K>J$ we have

$$
\begin{aligned}
\prod_{l=1}^{K}\left(1+H_{l}^{-1}\right)^{2 / J} & -\prod_{l=1}^{K} H_{l}^{-2 / J} \geqq \prod_{l=1}^{K}\left(1+H_{l}^{-2 K / J}\right)^{1 / K}-\prod_{l=1}^{K} H_{l}^{-2 / J} \\
& \geqq 1+\prod_{l=1}^{K} H_{l}^{-2 / J}-\prod_{l=1}^{K} H_{l}^{-2 / J}=1,
\end{aligned}
$$

where we have used Theorem 27 and 10 of [5] in the first and second inequalities respectively. Putting (1.9), (1.10) and (1.11) together gives the desired result.

Our upper bound in Corollary 4 sharpens an inequality in Stolarsky [9], p. 15.

We also remark that Corollary 4 has an interesting geometrical 
interpretation. Let $\vec{b}_{1}, \vec{b}_{2}, \cdots, \vec{b}_{J}$ denote nonzero column vectors in $\boldsymbol{R}^{K}$ with $\vec{b}_{j}^{T}=\left(b_{j 1} b_{j 2} \cdots b_{j K}\right)$. We write $\Lambda_{j}(\vec{x})=\left\langle\vec{b}_{j}, \vec{x}\right\rangle,\left\|\vec{b}_{j}\right\|=\left(\sum_{k=1}^{K}\left|b_{j k}\right|^{2}\right)^{1 / 2}$ and recall that $\left|\overrightarrow{\left\langle b_{j}\right.}, \vec{x}\right\rangle \mid\left\|\vec{b}_{j}\right\|^{-1}$ is the length of the projection of $\vec{x}$ onto the subspace spanned by the vector $\vec{b}_{j}$. Applying the corollary with $H_{1}=H_{2}=\cdots=H_{K}=H$ we find that there is always a nonzero lattice point $\vec{u} \in \boldsymbol{Z}^{K}$ with components at most $H$ in absolute value and having a projection onto the span of each $\vec{b}_{j}$ of length at most $2 H^{1-K / J}$.

2. Preliminary results. The remainder of our paper is devoted to a proof of Theorem 1 . This is accomplished by combining the following lemmas. Here we write $\delta_{j k}$ for the Kronecker delta and $B^{*}$ for the complex conjugate transpose of the matrix $B$.

Lemma 5. Let $B=\left(b_{j k}\right)$ be a $J \times K$ matrix with complex entries and let $D=\left(d_{k} \hat{o}_{j k}\right)$ be a diagonal matrix with $d_{k}>0$ for $k=1,2, \cdots, K$. Then

$$
\operatorname{det}\left(D+B^{*} B\right) \leqq\left(\prod_{l=1}^{K} d_{l}\right) \prod_{j=1}^{I}\left(1+\sum_{k=1}^{K} d_{k}^{-1}\left|b_{j k}\right|^{2}\right)
$$

It is possible to bound $\operatorname{det}\left(D+B^{*} B\right)$ by using Hadamard's inequality (Bellman [2], Gantmacher [4], p. 252). But the result we obtain is

$$
\operatorname{det}\left(D+B^{*} B\right) \leqq \prod_{k=1}^{K}\left(d_{k}+\sum_{j=1}^{J}\left|b_{j k}\right|^{2}\right),
$$

and this is generally weaker than (2.1) if $1 \leqq J<K$.

Proof of Lemma 5. Let $I_{K}$ denote the $K \times K$ identity matrix. We will begin by proving that

$$
\operatorname{det}\left(I_{K}+B^{*} B\right) \leqq \prod_{j=1}^{J}\left(1+\sum_{k=1}^{K}\left|b_{j k}\right|^{2}\right) .
$$

If $Q$ is a $K \times K$ unitary matrix, that is if $Q^{*} Q=Q Q^{*}=I_{K}$, then the left and right hand sides of (2.2) are unchanged when $B$ is replaced by $B Q$. Since $B^{*} B$ is a positive semi-definite Hermitian matrix we may choose the unitary matrix $Q$ so that $Q^{*} B^{*} B Q$ is a diagonal matrix. In particular we may choose $Q$ (see Gantmacher [4], p. 274) so that

$$
Q^{*} B^{*} B Q=(B Q)^{*}(B Q)=\left(\lambda_{k} \delta_{j k}\right)
$$

where 


$$
\lambda_{1} \geqq \lambda_{2} \geqq \cdots \geqq \lambda_{M}>0=\lambda_{M+1}=\lambda_{M+2}=\cdots=\lambda_{K} .
$$

Thus $\operatorname{rank}(B)=\operatorname{rank}\left(B^{*} B\right)=M \leqq K . \quad($ Of course if $\operatorname{rank}(B)=0$ then (2.2) is trivial so we may suppose that $1 \leqq M$.) By replacing $B$ by $B Q$ it follows that we may assume without loss of generality that $B^{*} B=\left(\lambda_{k} \delta_{j k}\right)$, or equivalently that

$$
\sum_{l=1}^{J} \bar{b}_{l j} b_{l k}=\lambda_{k} \delta_{j k} .
$$

Taking $j=k \geqq M+1$ in (2.3) we find that $b_{j k}=0$ if $k=M+1$, $M+2, \cdots, K$.

Next we define $w_{j k}=\lambda_{k}^{-1 / 2} b_{j k}$ so that by (2.3) the $J \times M$ matrix $W=\left(w_{j k}\right)$ has $M$ orthonormal columns (and so $M \leqq J$ ). It follows from Bessel's inequality that

$$
\sum_{k=1}^{M}\left|w_{j k}\right|^{2} \leqq 1
$$

for $j=1,2, \cdots, J$. Since $I_{K}+B^{*} B=\left(\left\{1+\lambda_{k l}\right\} \delta_{j k}\right)$ we have

$$
\begin{aligned}
\operatorname{det}\left(I_{K}+B^{*} B\right) & =\prod_{k=1}^{M}\left(1+\lambda_{k}\right)=\prod_{k=1}^{M}\left(1+\lambda_{k}\right)^{\Sigma_{j=1}^{J}\left|w_{j k}\right|^{2}} \\
& =\prod_{j=1}^{J}\left\{\prod_{k=1}^{M}\left(1+\lambda_{k}\right)^{\left|w_{j k}\right|^{2}}\right\} .
\end{aligned}
$$

Thus to establish (2.2) it suffices to show that

$$
\prod_{k=1}^{M}\left(1+\lambda_{k}\right)^{\left|w_{j k}\right|^{2}} \leqq 1+\sum_{k=1}^{K}\left|b_{j k}\right|^{2}
$$

for each $j=1,2, \cdots, J$. If $\sum_{k=1}^{M}\left|w_{j k}\right|^{2}=0$ then (2.5) is trivial since the left hand side is one. If $\sum_{k=1}^{M}\left|w_{j k}\right|^{2}>0$ then by the arithmeticgeometric mean inequality (see [5], Theorem 9) we have

$$
\begin{aligned}
\prod_{k=1}^{M}\left(1+\lambda_{k}\right)^{\left|w_{j k}\right|^{2}} & \leqq\left(\frac{\sum_{k=1}^{M}\left|w_{j k}\right|^{2}\left(1+\lambda_{k}\right)}{\sum_{k=1}^{M}\left|w_{j k}\right|^{2}}\right)^{\sum_{k=1}^{M}\left|w_{j k}\right|^{2}}=\left(1+\frac{\sum_{k=1}^{M}\left|b_{j k}\right|^{2}}{\sum_{k=1}^{M}\left|w_{j k}\right|^{2}}\right)^{\sum_{k=1}^{M}\left|w_{j k}\right|^{2}} \\
& \leqq\left(1+\sum_{k=1}^{M}\left|b_{j k}\right|^{2}\right)=\left(1+\sum_{k=1}^{K}\left|b_{j k}\right|^{2}\right) .
\end{aligned}
$$

In the last inequality we have used (2.4) together with the observation that $(1+(c / x))^{x}$ is an increasing function of $x$ for $x>0$ and any fixed $c \geqq 0$. This proves (2.2).

To complete the proof of the lemma we note that

$$
\begin{aligned}
\operatorname{det}\left(D+B^{*} B\right) & =\operatorname{det}\left(D^{1 / 2}\right) \operatorname{det}\left(I_{K}+D^{-1 / 2} B^{*} B D^{-1 / 2}\right) \operatorname{det}\left(D^{1 / 2}\right) \\
& =\left(\prod_{k=1}^{K} d_{k}\right) \operatorname{det}\left(I_{K}+\left(B D^{-1 / 2}\right)^{*}\left(B D^{-1 / 2}\right)\right)
\end{aligned}
$$




$$
\leqq\left(\prod_{k=1}^{K} d_{k}\right) \prod_{j=1}^{J}\left(1+\sum_{k=1}^{K} d_{k}^{-1}\left|b_{j k}\right|^{2}\right)
$$

Next we suppose that $L_{j}(\vec{x}), j=1,2, \cdots, N$ are $N$ linear forms in $K$ variables,

$$
L_{j}(\vec{x})=\sum_{k=1}^{K} a_{j k} x_{k},
$$

so that $A=\left(a_{j k}\right)$ is an $N \times K$ matrix. We assume that the forms $L_{j}$ are real for $j=1,2, \cdots, r$ and that the remaining forms consist of $s$ pairs of complex conjugate forms arranged so that $L_{r+2 j-1}=$ $\bar{L}_{r+2 j}$ for $j=1,2, \cdots, s$. Let $\varepsilon_{1}, \varepsilon_{2}, \cdots, \varepsilon_{N}$ be positive with $\varepsilon_{r+2 j-1}=$ $\varepsilon_{r+2 j}$ for $j=1,2, \cdots, s$. We define the $N \times N$ diagonal matrix $E$ by $E=\left(c_{j} \delta_{j k}\right)$ where $c_{j}=\varepsilon_{j}^{-1}$ if $j=1,2, \cdots, r$ and $c_{j}=(2 / \pi)^{1 / 2} \varepsilon_{j}^{-1}$ if $j=r+1, r+2, \cdots, N$.

Lemma 6. Let $M$ be a positive integer and suppose that

$$
M\left|\operatorname{det} A^{*} E^{2} A\right|^{1 / 2} \leqq 1 .
$$

Then there exist at least $M$ distinct pairs of nonzero lattice points $\pm \vec{v}_{m}, m=1,2, \cdots, M$, in $Z^{K}$ such that

$$
\left|L_{j}\left( \pm \vec{v}_{m}\right)\right| \leqq \varepsilon_{j}
$$

for each $j=1,2, \cdots, N$ and each $m=1,2, \cdots, M$.

For a proof of Lemma 6 we refer to [10].

3. Proof of Theorem 1. Let $N=J+K$. We apply Lemma 6 with

$$
\begin{aligned}
& L_{j}(\vec{x})=x_{j}, \quad j=1,2, \cdots, K, \\
& L_{K+j}(\vec{x})=\Lambda_{j}(\vec{x}), \quad j=1,2, \cdots, J .
\end{aligned}
$$

Thus $r=K+p$ and $s=q$. The matrix $A$ can then be partitioned as

$$
A=\left(\begin{array}{c}
I_{K} \\
B
\end{array}\right)
$$

We also let

$$
\begin{aligned}
& \varepsilon_{j}=\alpha_{j}, \quad j=1,2, \cdots, K, \\
& \varepsilon_{K+j}=\beta_{j}, \quad j=1,2, \cdots, p, \\
& \varepsilon_{K+j}=\left(\frac{2}{\pi}\right)^{1 / 2} \beta_{j}, \quad j=p+1, p+2, \cdots, J .
\end{aligned}
$$


Using (3.1) it follows that

$$
A^{*} E^{2} A=D+(G B)^{*}(G B)
$$

where $D=\left(\alpha_{k}^{-2} \delta_{j k}\right)$ is a $K \times K$ diagonal matrix and $G=\left(\beta_{j}^{-1} \delta_{j k}\right)$ is a $J \times J$ diagonal matrix. Combining (1.1), (3.2) and Lemma 5 we find that

$$
M^{2} \operatorname{det}\left(A E^{2} A^{*}\right) \leqq 1 .
$$

Thus the conclusion of Theorem 1 follows as an application of Lemma 6.

\section{REFERENCES}

1. A. Baker, Transcendental Number Theory, Cambridge University Press, 1975.

2. R. Bellman, Introduction to Matrix Analysis, McGraw-Hill, 1970.

3. A. O. Gel'fond, Transcendental and Algebraic Numbers, Dover, 1960.

4. F. R. Gantmacher, The Theory of Matrices, Vol. 1, Chelsea, 1959.

5. G. H. Hardy, J. E. Littlewood and G. Polya, Inequalities, 2nd. ed., Cambridge University Press, 1952.

6. K. Mahler, On a problem in Diophantine approximation, Arch. Math., 6 (1955), 208214.

7. L. J. Mordell, Diophantine Equations, Academic Press, 1969.

8. C. L. Siegel, Transcendental Numbers, Princeton, 1949.

9. K. B. Stolarsky, Algebraic Numbers and Diophantine Approximation, Dekker, 1974.

10. J. D. Vaaler, A geometric inequality with applications to linear forms, Pacific J. Math., 83 (1979), 543-553.

Received June 1, 1979. This research was supported by the National Science Foundation, grant MCS 77-01830.

The University of Texas

Austin, TX 78712 


\section{PACIFIC JOURNAL OF MATHEMATICS}

\section{EDITORS}

DONALD BABBITT (Managing Editor)

University of California

Los Angeles, CA 90024

Hugo RossI

University of Utah

Salt Lake City, UT 84112

C. C. MOORE and ANDREW OGG

University of California

Berkeley, CA 94720

\section{J. DugunduI}

Department of Mathematics

University of Southern California

Los Angeles, CA 90007

R. Finn and J. Milgram

Stanford University

Stanford, CA 94305

\section{ASSOCIATE EDITORS}
E. F. BeCKenBACH
B. H. NeumanN
F. WOLF
K. YosHIDA

\section{SUPPORTING INSTITUTIONS}

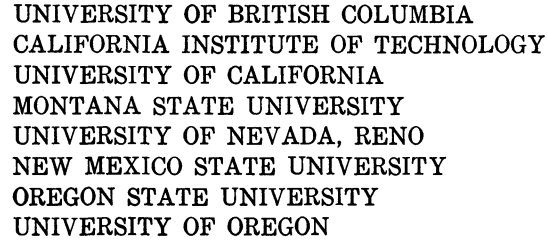

UNIVERSITY OF BRITISH COLUMBIA CALIFORNIA INSTITUTE OF TECHNOLOGY UNIVERSITY OF CALIFORNIA

MONTANA STATE UNIVERSITY

UNIVERSITY OF NEVADA, RENO

NEW MEXICO STATE UNIVERSITY

OREGON STATE UNIVERSITY UNIVERSITY OF OREGON

\author{
UNIVERSITY OF SOUTHERN CALIFORNIA \\ STANFORD UNIVERSITY \\ UNIVERSITY OF HAWAII \\ UNIVERSITY OF TOKYO \\ UNIVERSITY OF UTAH \\ WASHINGTON STATE UNIVERSITY \\ UNIVERSITY OF WASHINGTON
}

The Supporting Institutions listed above contribute to the cost of publication of this Journal, but they are not owners or publishers and have no responsibility for its content or policies.

Mathematical papers intended for publication in the Pacific Journal of Mathematics should be in typed form or offset-reproduced, (not dittoed), double spaced with large margins. Please do not use built up fractions in the text of the manuscript. However, you may use them in the displayed equations. Underline Greek letters in red, German in green, and script in blue. The first paragraph or two must be capable of being used separately as a synopsis of the entire paper. Please propose a heading for the odd numbered pages of less than 35 characters. Manuscripts, in triplicate, may be sent to any one of the editors. Please classify according to the scheme of Math. Reviews, Index to Vol. 39. Supply name and address of author to whom proofs should be sent. All other communications should be addressed to the managing editor, or Elaine Barth, University of California, Los Angeles, California, 90024.

50 reprints to each author are provided free for each article, only if page charges have been substantially paid. Additional copies may be obtained at cost in multiples of 50 .

The Pacific Journal of Mathematics is issued monthly as of January 1966. Regular subscription rate: $\$ 84.00$ a year (6 Vols., 12 issues). Special rato: $\$ 42.00$ a year to individual members of supporting institutions.

Subscriptions, orders for numbers issued in the last three calendar years, and changes of address shoud be sent to Pacific Journal of Mathematics, P.O. Box 969, Carmel Valley, CA 93924, U.S.A Old back numbers obtainable from Kraus Periodicals Co., Route 100, Millwood, NY 10546.

PUBLISHED BY PACIFIC JOURNAL OF MATHEMATICS, A NON-PROFIT CORPORATION

Printed at Kokusai Bunken Insatsusha (International Academic Printing Co., Ltd.). 8-8, 3-chome, Takadanobaba, Shinjuku-ku, Tokyo 160, Japan.

Copyright (C) 1980 by Pacific Jounal of Mathematics Manufactured and first issued in Japan 


\section{Pacific Journal of Mathematics \\ Vol. 90, No. $2 \quad$ October, 1980}

Frank Hayne Beatrous, Jr., Hölder estimates for the $\bar{\partial}$ equation with a support condition ..................................... 249

Charles L. Belna, Michael Jon Evans and Paul Humke, Planar continua

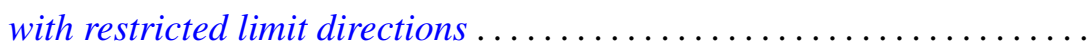

Leon Brown and Takashi Ito, Classes of Banach spaces with unique isometric preduals................................. 261

V. K. Deshpande, Completions of Noetherian hereditary prime rings ..... . 285

Deepak Dhar, Asymptotic enumeration of partially ordered sets . . . . . . . 299

Zeev Ditzian, On interpolation of $L_{p}[a, b]$ and weighted Sobolev

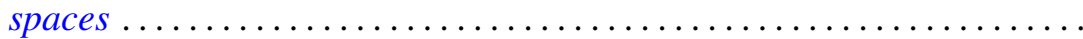

Andrew George Earnest, Congruence conditions on integers represented by

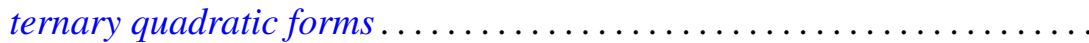

Melvin Faierman, Bounds for the eigenfunctions of a two-parameter system of ordinary differential equations of the second order ..............

Hector O. Fattorini, Vector-valued distributions having a smooth

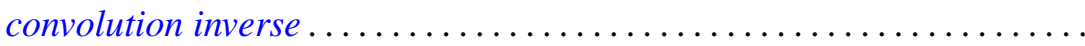

Howard D. Fegan, The spectrum of the Laplacian on forms over a Lie

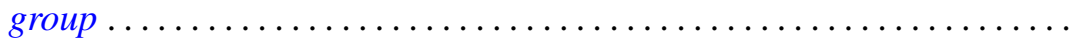

Gerald Leonard Gordon, On the degeneracy of a spectral sequence associated to normal crossings..

S. Madhavan, On bisimple weakly inverse semigroups ... 397

Françoise Mathot, On the decomposition of states of some

Roger McCann, Embedding asymptotically stable dynamical systems into radial flows in $l_{2}$

Michael L. Mihalik, Ends of fundamental groups in shape and proper homotopy...............................

Samuel Murray Rankin, III, Boundary value problems for partial functional differential equations .

Randy Tuler, Arithmetic sums that determine linear characters on $\Gamma(N)$

Jeffrey D. Vaaler, On linear forms and Diophantine approximation ..

G. P. Wene, Alternative rings whose symmetric elements are nilpotent or a right multiple is a symmetric idempotent. . 